\title{
Tiene un lugar la educación religiosa en la escuelai Una aproximación desde el contexto Colombiano ${ }^{1}$
}

\author{
Há um lugar para o ensino religioso na escola? \\ Uma abordagem do contexto Colombiano
}

\begin{abstract}
Juan Manuel Torres Serrano
Ph.D en Teología, docente de pregrado y Post-Grado, director del Programa de Licenciatura en Educación Religiosa de la Universidad de la Salle, Bogotá - Colômbia, e-mail: jtorres@lasalle.edu.co
\end{abstract}

No podemos tomar todo cuando salimos de viaje en medio de la vida. Partimos. Olvidamos las limitaciones de las instituciones y de los proyectos de los otros. Olvidamos las evaluaciones y acreditaciones exteriores. Dejamos los roles y llegamos al yo. Si pudiera dar un regalo a aquellos que comienzan el viaje sería una tienda. Una tienda porque es algo provisional. Sería como regalar raíces

1 El artículo no pretende abordar el complejo y vasto contexto de la Educación religiosa Escolar en Colombia, de acuerdo a la situación diversa de sus regiones, ni mucho menos pretende un estudio diacrónico-evolutivo de la misma. El referente que utilizará el artículo para acercarse al contexto es el documento: "Lineamientos y estándares curriculares para el área de Educación religiosa”. 2004 y la Ley General de Educación (MINISTERIO DE LA EDUCACIÓN NACIONAL. Republica da Colombia. Ley 115 de 1994 de 8 de febrero de 1994. Por la cual se expide la ley general de educación. Diario Oficial, n. 41.214, de 8 de febrero de 1994. Disponible en: <http://menweb.mineducacion.gov.co/normas/concordadas/Decreto115.htm>. Acceso en: 20 sept. 2011). El artículo es resultado parcial del proyecto de investigación sobre "Itinerarios de Creencias de Jóvenes en Colegios de la Salle”. Dicho proyecto se realiza interinstitucionalmente con la Université Laval. Qc. Canadá. 
portátiles... Cada uno tiene la oportunidad de renacer, auténticamente único, con una capacidad acrecentada de amarse a sí mismo $y$ de abrir los brazos a los otros (SHEEHY, 1976, p. 364-513).

\section{Resumen}

Las relaciones estrechas entre Iglesia-estado, la consideración del catolicismo como religión mayoritaria, la influencia de la Iglesia católica en la sociedad Colombiana, la tradición católica heredada y traducida en un cristianismo nominalista y sociológico, el número de instituciones educativas privadas manejadas por comunidades religiosas católicas hacen que la pregunta por el lugar de la Educación Religiosa Escolar en la escuela se considere desde marcos confesionales, eclesiocéntricos, evangelizadores y catequísticos. Sin embargo el lugar de la Educación Religiosa en la escuela se ve interpelado, cuestionado y desafiado por una sociedad global, plural y democrática. Las prácticas deliberativas, comunicativas, autónomas de las sociedades modernas interrogan la práctica educativa y la formación de la Educación religiosa escolar en Colombia. La educación y la escuela en su dimensión pública, integrando e interactuando con la sociedad deben tomar en serio el pluralismo religioso y cultural. Comprender el sentido de lo religioso-trascendental, en el marco de las búsquedas de sentido humanas, debe promover el aprender a vivir juntos, la construcción de identidad y el reconocimiento de la diversidad.

Palabras-clave: Educación religiosa escolar. Reconocimiento. Pluralismo religioso. Cultura.

\section{Resumo}

As estreitas relações entre Igreja e Estado, a consideração do Catolicismo como a religião da maioria, a influência da Igreja Católica na sociedade colombiana, a tradição católica herdada e traduzida em um cristianismo nominal e sociológico, o número de instituições de ensino privado gerenciadas por comunidades religiosas Católicas fazem que a questão sobre um lugar para o Ensino Religioso na escola seja avaliada com base em marcos de fé, eclesiocentrismo, evangelística e catequética. No entanto, o lugar do ensino religioso na escola é interpelado, questionado e desafiado por uma sociedade global, plural e democrática. Práticas deliberativas, de comunicação e autônomas das sociedades modernas questionam práticas de ensino e formação do Ensino Religioso escolar na Colômbia. A educação e a escola em sua dimensão 
pública, integrando e interagindo com a sociedade, devem levar a sério o pluralismo religioso e cultural. Entender o significado do religioso-transcendental, como parte da busca humana de sentido, deve promover o aprendizado para a vida em comunidade, a construção da identidade e o reconhecimento da diversidade.

Palavras-chave: Educação religiosa escolar. Reconhecimento. Pluralismo religioso. Cultura.

\section{Introducción}

La pregunta por el lugar y estatus dela Educación Religiosa en la Escuela ${ }^{2}$ (ERE) continúa desafiando la reflexión y praxis de educadores e instituciones educativas privadas y públicas en el contexto Colombiano. Desafíos que se traducen en preguntas como: cuál es el objeto de estudio de la Educación Religiosa Escolar? Qué tareas y retos le plantea una sociedad pluricultural y plurireligiosa? Es finalidad de la Educación Religiosa Escolar catequizar y evangelizar? Cuál es el lugar de la Educación Religiosa Escolar frente a la secularización y laicización que vive la sociedad? De acuerdo a la libertad de cultos que promulga la constitución colombiana, es solo tarea de la Iglesia Católica definir lineamientos y estándares curriculares para la Educación Religiosa Escolar? Qué exigencias y tareas plantea la situación particular de los sujetos, la Escuela, la sociedad colombiana al currículo de la Educación Religiosa Escolar?

La respuesta a la pregunta por el lugar de la Educación Religiosa en la escuela - teniendo en cuenta el clima socio-religioso de nuestro país, de una religión católica mayoritaria, de los vínculos todavía estrechos entre Iglesia/estado/sociedad, de un gran número de instituciones educativas privadas manejadas por comunidades religiosas - parece evidente: tiene lugar la Educación Religiosa Escolar confesionalmente católica en la escuela. Sin embargo en la realidad, sobre todo en las Escuelas públicas, el panorama no es tan homogéneo y la respuesta no es tan evidente.

2 Entiéndase escuela fundamentalmente la educación básica secundaria. 
A pesar que la Iglesia Católica Colombiana, a través de la Conferencia Episcopal, ha venido definiendo la naturaleza, objetivos y contenidos de la Educación Religiosa Escolar, no ha habido un diálogo entre Ministerio de Educación - Escuela (sobre todo pública) - Iglesia católica y otras religiones que salvaguarde la libertad de cultos, de religión promulgado por la constitución colombiana y por la ley general de Educación de 1994.

La responsabilidad que ha asumido la Iglesia Católica Colombiana de cara a la Educación Religiosa Escolar-confesional es coherente con su misión evangelizadora a nivel educativo, pero igualmente es urgente, desde referentes constitucionales, legales y sobre todo desde el contexto de sociedades cada vez más plurales, complejas, globales, democráticas, tomarse en serio un diálogo macro-ecuménico entre religiones-sociedad-cultura-Escuela que aporte a las búsquedas humanas de sentido, a la comprensión de la dimensión religiosa en la cultura y la persona, y el saber vivir juntos como ciudadanos de la aldea global.

Este artículo tiene como finalidad presentar el lugar que tiene la Educación Religiosa Escolar según lo plantea la Conferencia Episcopal Colombiana y confrontar dicho lugar con referentes educativos y teóricos con el fin de descubrir prospectivas y nuevos horizontes de comprensión de la Educación Religiosa, de su finalidad y su objeto de estudio. Es por ello que en primer lugar se presentará una breve aproximación al contexto actual de la Educación Religiosa Escolar (Naturaleza y finalidad) desde la ley 115 y el documento de la CEC de 2004; en segundo lugar se confrontará dicho contexto con una breve aproximación teórica a la política de reconocimiento-diferencia según Charles Taylor y la situación actual de la Enseñanza ética y religiosa en la Provincia de Quebec ${ }^{3,4}$. Finalmente se plantearán prospectivas y horizontes de comprensión sobre la finalidad y naturaleza de la Educación Religiosa Escolar.

3 Cabe aclarar que dicha confrontación no pretende transpolar o aplicar a-críticamente contenidos, finalidades de un contexto quebequense-francófono al contexto colombiano. Por el contrario, en esta "fusión de horizontes" se busca replantear nuevas preguntas, nuevos horizontes de comprensión en el contexto de la Educación Religiosa en Colombia. Cabe aclarar también que se ha puesto la vista en el ambiente educativo quebequense-francófono debido a que en ellos se ha tomado en serio la cuestión del pluralismo cultural y religioso y el respeto a la autonomía y la libertad religiosa. Este contexto puede convertirse, entre tantos otros, en un buen referente para observar una propuesta educativa religiosa.

4 Esta aproximación al reconocimiento, se hará desde el libro de TAYLOR, C. Grandeur et misère de la modernité. Canadá: Bellarmin, 2007. p. 59. 


\section{Aproximación a la naturaleza, justificación y objetivos de la educación religiosa escolar en la Ley $\mathbf{1 1 5}$ y el documento sobre lineamientos y estándares curriculares para el área de educación religiosa de 2004}

Según la Ley General de Educación colombiana (Ley 115 de 1994) la Educación Religiosa Escolar es un área fundamental y obligatoria del conocimiento y de la formación para el logro de los objetivos de la Educación básica secundaria. Según el artículo 23 de la Ley 115: "La Educación Religiosa se ofrecerá en todos los establecimientos educativos, observando la garantía constitucional según la cual, en los establecimientos del Estado ninguna persona podrá ser obligada a recibirla". En el artículo 24 se afirma que: "[...] los establecimientos educativos la establecerán sin perjuicio de las garantías institucionales de libertad de conciencia, libertad de cultos, la libertad religiosa y el derecho de los padres a escoger el tipo de educación para sus hijos menores".

Por otro lado la Conferencia Episcopal Colombiana a través de la Comisión Episcopal para la Evangelización de la Cultura y de la Educación ha elaborado un documento de trabajo y de consulta titulado: "Lineamientos y estándares curriculares para la Educación Religiosa" (2004), donde se subraya que, según el concordato de 1973, es competencia de la Iglesia, en el desarrollo de su misión apostólica, la elaboración de Programas y la elaboración de los textos para la Educación Religiosa Católica. Junto al concordato se despliegan argumentos desde una cierta continuidad con documentos definidos por la Conferencia Episcopal Colombiana como: "Orientaciones pastorales y contenidos para los Programas de Enseñanza Religiosa Escolar" de 1992; "Guía para el desarrollo de los programas de Educación Religiosa en primaria" de 1993 y "Guía para el desarrollo de los programas de Educación Religiosa en básica secundaria y educación media” de 1993.

En el documento de "Lineamientos y estándares curriculares para la Educación Religiosa" (2004) se afirma que la necesidad de la Educación Religiosa Escolar está relacionada con las necesidades del sujeto educativo

5 Para profundizar en la justificación de la Educación Religiosa Escolar y la importancia del hecho religioso en la sociedad y la cultura remitirse al documento: CONFERENCIA EPISCOPAL COLOMBIANA. Escuela y religión. Colombia: Conferencia Episcopal, 2000. 
y de su desarrollo humano e integral. La ERE responde a la necesidad de crecimiento en aspectos de su desarrollo humano como (CONFERENCIA EPISCOPAL COLOMBIANA, 2004, p. 56): antropológicos (los estudiantes necesitan respuestas a los problemas que conciernen la búsqueda de sentido y la dimensión trascendente-religiosa de la vida); éticos (los estudiantes necesitan iniciarse a la acción ética e interpretar un cuadro axiológico que se originan en la experiencia de fe cristiana y en el patrimonio religioso propio de la cultura); psicológicos (los estudiantes necesitan formarse una identidad, integrar su personalidad y valorar el aporte de la experiencia religiosa en este proceso); epistemológicos (los estudiantes necesitan cultivar diversas formas de acercamiento, conocimiento y expresión de la realidad); pedagógicos (los estudiantes necesitan aprender a aprender y saber; necesitan aprender a plantearse el problema de lo religioso y aprender a manejar las fuentes para estudiar la revelación cristiana); histórico culturales (los estudiantes necesitan valorar e interpretar el patrimonio religioso local y global en el cual se destaca la incidencia del cristianismo); sociales (los estudiantes necesitan identificar la función de la religión y su aporte al desarrollo humano y social); derechos humanos (los estudiantes tienen derecho a recibir una educación integral que no deje de lado la dimensión religiosa de la cultura y de la persona).

Por otra parte el documento de trabajo y consulta (2004), una vez justifica la necesidad de la Educación Religiosa en la Escuela, se acerca al tipo o forma de presencia de lo religioso en la Escuela y diferencia enfoques y modelos de Educación Religiosa para posteriormente definir cuál es el más característico de la Escuela. En primer lugar el documento presenta los modelos de Educación Religiosa según el medio institucional (CONFERENCIA EPISCOPAL COLOMBIANA, 2004, p. 7-8). En el que los desarrolla, diferenciando la Educación religiosa familiar; Educación Religiosa en la Iglesia (donde se destaca la catequesis, considerada como la forma más completa y eminente de educación en la fe. Junto a la catequesis toda la acción misionera y pastoral de la Iglesia tiene una finalidad de educación en la fe. Una de las modalidades de esta educación es la escolar); Educación Religiosa Escolar (que se desarrolla en el marco de la educación formal, que se desarrolla en relación con los fines de la educación media, básica y educación superior). 
En segundo lugar el documento presenta los modelos de Educación Religiosa según el objeto de estudio y los objetivos que se busca (CONFERENCIA EPISCOPAL COLOMBIANA, 2004, p. 7-8), diferenciando la Educación Religiosa como: Cultura Religiosa (el objeto de estudio es lo "religioso" como elemento de la cultura y como estudio comparado de las religiones. Son no confesionales, donde se busca un conocimiento de las manifestaciones religiosas y un respeto a las mismas); Educación en valores (el objeto de estudio son los valores y las normas de convivencia; se busca el desarrollo de la sensibilidad hacia el respeto mutuo y la ética ciudadana. Se considera implícitamente que lo religioso se refiere a los valores éticos sin considerar los aspectos de la tradición religiosa); Conocimiento de la propia religión (el objeto de estudio son los elementos de un credo particular y se busca facilitar a los padres de familia el que sus hijos reciban la educación que corresponde a sus creencias, colaborando al estudiante en el descubrimiento de su identidad religiosa y a reconocer y respetar otros credos).

En tercer lugar el documento presenta los modelos de Educación Religiosa según el enfoque de desarrollo pedagógico y didáctico (CONFERENCIA EPISCOPAL COLOMBIANA, 2004, p. 11-12), haciendo distinción entre Educación religiosa como actividades pastorales (através de actos de culto, convivencias, retiros que buscan desarrollar la dimensión religiosa y de fe cristiana por medio de experiencias religiosas, de celebración y expresión de fe); Educación Religiosa como proyecto pedagógico interdisciplinario (no se asigna tiempo, contenido y docente específico, sino a varias áreas y docentes el desarrollo de proyectos interdisciplinares que buscan el desarrollo de los valores); Educación Religiosa como acción transversal (se desarrolla como eje transversal a todas las áreas y no se asigna tiempo, contenido y docente específico. Se asume que cada docente y cada área esta llamada a evangelizar y a desarrollar una dimensión religiosa); Educación Religiosa como área del conocimiento y de la formación (con estándares, docentes, tiempos y contenidos específicos. Se orienta al conocimiento religioso con fines formativos, integrando otras áreas de conocimiento).

Finalmente el documento plantea el modelo de educación religiosa según la responsabilidad de su gestión (CONFERENCIA EPISCOPAL 
COLOMBIANA, 2004, p. 13-14), diferenciando la Educación como responsabilidad eclesial (función exclusiva de la Iglesia), como responsabilidad de la familia (un determinado tipo de Educación Religiosa se haría según el concepto de los Padres de Familia que eligen un tipo de formación religiosa para sus hijos); como responsabilidad de la escuela (definida por la institución según su autonomía escolar); como responsabilidad compartida (donde se reconoce el derecho y función de cada agente educativo y social. Estado, Iglesia, familia y escuela se unen para acordar y realizar dicha educación en el marco de acuerdos que faciliten ese trabajo común).

Una vez hechas estas distinciones el documento afirma que la Educación Religiosa Escolar es una acción evangelizadora y educativa que “[...] fomenta el conocimiento de la propia religión a través de los métodos propios de un área de conocimiento y la formación, y gestionada en forma compartida por la escuela, la Iglesia y la familia" (CONFERENCIA EPISCOPAL COLOMBIANA, 2004, p. 14). Como acción educativa escolar el área de Educación Religiosa no sustituye la Educación Religiosa familiar, la catequesis u otras formas de educación religiosa que se ofrecen al interior de la Iglesia, pero tampoco se contrapone a ellas buscando articulación con miras al desarrollo de la dimensión religiosa y la educación en la fe.

Como conocimiento de la propia religión la Educación Religiosa propone garantizar a los padres de familia aquella que se ajuste a sus convicciones; se propone igualmente aplicar el principio de diálogo interreligioso y ecuménico que permita a los estudiantes, conociendo su propio credo religioso, conocer otros credos, fomentar el respeto mutuo y la interculturalidad. La Educación Religiosa busca articular sus objetivos con los fines de la educación - confesionales en la escuela privada como la católica y no confesionales en la escuela pública- ${ }^{6}$ y con los de la educación en la fe. Como área del conocimiento y la formación la Educación

\footnotetext{
6 Según Fernand Quellet La escuela moderna-pública, a diferencia de las escuelas religiosas-privadas a las cuales la legitimidad es reconocida por el derecho internacional, no tiene como objetivo reproducir los particularismos identitarios de aquellos que la frecuentan. La génesis de la escuela moderna, su existencia y desarrollo, se encuentra ligada al lugar preponderante dado a una educación para todos que busca preparar la participación de cada ciudadano a la acción de la colectividad. Cf. QUELLET, F. Quelle fomation pour l'éducation à la religión. Quèbec: Presses de l'Université Laval, 2005. p. 13.
}

Rev. Pistis Prax., Teol. Pastor., Curitiba, v. 4, n. 1, p. 197-214, jan./jun. 2012 
Religiosa se desarrolla mediante procesos académicos de investigación y conocimiento. Se presenta como propuesta didácticamente organizada a través de forma de enseñanza-aprendizaje que tiene en cuenta criterios de coherencia psicopedagógica, científica y cultural; con capacidad de estructurarse como cuerpo de conocimientos, valores, habilidades y estrategias cognitivas que facilitan la construcción y apropiación del conocimiento, ayudando a los estudiantes a valorar, interpretar, conceptualizar y valorar la experiencia religiosa.

La ERE se considera como disciplina escolar y acción evangelizadora. En cuanto disciplina escolar ella está integrada a la actividad propia de la escuela y se desarrolla en el marco de los principios generales de la educación colombiana sobre las áreas fundamentales y obligatorios que se establecen en el artículo 23 de la ley 115 de 1994 y con los objetivos y fines de la educación contemplados en la misma ley. Dos elementos más la definen como disciplina escolar: su justificación y fundamentación al servicio del desarrollo humano del educando y su exigencia de rigor y sistematicidad. Es acción evangelizadora en cuanto que ella: cumple el mandato misionero de Cristo; se realiza en comunión con la Iglesia integrada a los planes pastorales de la Iglesia local y universal; participa del primer anuncio del Evangelio como llamada a la conversión, a la profesión de fe, y la inserción de la comunidad eclesial; participa del fin iniciatorio de la catequesis, en cuanto inicia en el conocimiento del mensaje cristiano contribuyendo a estructurar la vida cristiana. Este carácter evangelizador se manifiesta en el hecho que esta educación está articulada a los fines y objetivos de la Educación cristiana. En esta perspectiva el documento presenta los aportes que la Educación religiosa a cada uno de los objetivos de la educación definidos por la ley 115 y al mismo tiempo los aportes de la Educación Religiosa al logro de los fines de la Educación de la fe presentados por el Directorio General de la Catequesis.

Según este documento las competencias básicas para la Educación Religiosa Escolar son: saber comprender (que hace referencia a la capacidad de comprender e interpretar la experiencia humana desde la experiencia cristiana desde lo bíblico, litúrgico, moral, cultual y dogmático); saber dar razón de la fe (se refiere a la capacidad de realizar procedimientos y formas de explicación, investigación y expresión de los lenguajes 
religiosos, identificando su sentido y valor y correlacionándolo con la cultura y otros saberes); saber integrar fe y vida (hace referencia al desarrollo de valores y actitudes que den cuenta de la fe, valorando el aporte de la fe cristiana al proceso de desarrollo social y personalización); saber aplicar a la realidad (se refiere a la capacidad de aplicar el saber religioso a la realidad social-personal buscando el cambio).

\section{La confrontación de la identidad cristiana con el reconocimiento y la diversidad}

Sin pretender un estudio sistemático del documento de la Conferencia Episcopal Colombiana (2004) es pertinente presentar ciertos comentarios críticos. En primer lugar se ignora, en el contexto de la libertad de cultos y de religiones, la responsabilidad que tienen otras religiones en la Educación Religiosa; si la Educación religiosa es una responsabilidad compartida con la Iglesia, la Escuela y la familia, en una sociedad plurireligiosa es fundamental escuchar y articular el aporte de otros credos. La responsabilidad de la Educación Religiosa Escolar confesional no puede reducirse a una Iglesia particular, y a una sociedad y familia que en un régimen de cristiandad lo que hacen es reproducir el sistema dogmático, moral y cultual del catolicismo. Es innegable que la Iglesia católica tiene una responsabilidad en la Educación Religiosa Escolar, pero no puede reducirse a ella, ni mucho desconocer otros agentes sociales y religiosos que tienen el derecho de tomar la palabra.

En segundo lugar una Educación Religiosa que se "ajuste" a las convicciones de los padres de familia desconoce los procesos autónomos de construcción de la identidad de cristianos de los sujetos; la fe heredada continua primando sobre la fe pensada, deliberada. El documento parece preocuparse por garantizar una Educación Religiosa que responda a la tradición familiar y no a la situación, a las realidades históricas emergentes donde se configuran nuevas subjetividades, donde los sujetos devienen. Detrás de esta primacía de la "herencia religiosa familiar" se diluye el sujeto que, desde la acción y la interacción con otros, se representa y se inscribe en el mundo de manera dramática y singular. 
En tercer lugar se evidencia en el documento una correlación no diferenciada entre Educación Religiosa Escolar y Educación en la fe; una vez se concibe la Educación religiosa en el marco de la misión evangelizadora, catequética de la Iglesia ella parece colocarse al servicio del primer anuncio del evangelio y de la confesión de fe; en esta perspectiva esta centralidad catequética y pastoral prima sobre una Educación Religiosa que debe responder a contextos, sujetos cada vez más plurales. El documento reconoce que es importante articular los fines de la Educación Religiosa confesional en lo privado y no confesional en lo público, con los fines de la Educación según la ley 115 y los de la Educación en la fe según el Directorio general de la catequesis. Esta tarea no es fácil cuando lo confesional, lo pastoral, lo evangelizador y catequístico prima sobre la autonomía y legitimidad de los otros objetivos educativos. En esta perspectiva se evidencia en el documento el "imperialismo" y "servilismo" de la Educación Religiosa Escolar; imperialismo que se traduce en el esfuerzo por colocar de manifiesto el aporte de la Educación Religiosa Escolar - confesional, evangelizadora, catequizadora- a los fines de la Educación según la Ley 115 y no viceversa; servilismo que se manifiesta en la poner la Educación Religiosa al servicio de la Educación en la fe, desconociendo la dimensión pública, plural y democrática de la Escuela como institución social.

Me atrevería a afirmar que en el fondo del documento se encuentra la cuestión de la identidad cristiana y de la significación que ella tiene para las sociedades y las personas. Pero la identidad cristiana no puede absolutizarse en detrimento de la construcción de la identidad de seres humanos en interacción con otros. Si la Educación Religiosa Escolar toma en serio las necesidades de los sujetos, debe igualmente considerar con el mismo cuidado la relación entre identidad-reconocimiento-diferencia.

Teniendo en cuenta los objetivos de la educación, de la formación integral e integrador, de la gestión y construcción del conocimiento en las sociedades modernas, la Escuela no puede convertirse en una "nueva parroquia", ni la Iglesia católica puede pretender convertirla en dispositivo para cristianizar y convertir. Considerando la acción educativa como acción pública-política y la escuela institución social al interior y en relación con culturas, instituciones y agentes sociales plurales, la Educación Religiosa Escolar confesional debe estar preparada para deliberar, para 
"colocar en suspenso" sus "únicas y absolutas verdades"; para superar la asimetría que produce el considerar la existencia de religiones naturales y reveladas; para proponer, exponer y exponerse en la pluralidad cultural y religiosa. El lugar de la Educación Religiosa Escolar en la escuela no está dado de una vez por todas por el poder de instituciones religiosas sino que se construye continuamente en: la deliberación, inteligibilidad, razonabilidad y hasta falseabilidad misma de los saberes religiosos; la posibilidad de asumir curricularmente la autonomía y el aporte de otros saberes, de integrar más que de asimilar - no sólo de la interdisciplinariedad, sino de la transdiciplinariedad, de un diálogo entre saberes a través de metacategorías; la relación crítica y performativa entre identidad religiosaidentidad cultural-reconocimiento de la diversidad, de la otredad.

En este contexto se reconoce el valor de los aportes teórico del filósofo-católico Charles Taylor entorno a la correlación entre identidad-reconocimiento. Según Taylor (2006, p. 59) el ser humano es un ser que tiene necesidad de identidad, un ser que es capaz de conciencia reflexiva y que es llevado a orientarse en un espacio de cuestionamientos sobre el bien y el valor de las cosas: "el ser viviente es un ser capaz de pensar, actuar, decidir, de sentir emociones, de reaccionar y de entrar en relación con los otros" (TAYLOR, 1998, p. 87). El ejercicio de estas capacidades humanas enraíza el "уo" en una cultura, en una tradición: "La identidad de un individuo es hecha de su manera particular de situarse dentro de un universo cultural" (TAYLOR, 1998, p. 87). La identidad no es por lo tanto un dato puro y fijo, ella se construye en un proceso continuo de auto-definición a través de encuentros con los otros.

Esta identidad exige que los seres humanos sepan definir por ellos mismos aquello que da sentido a la vida: "Nuestra identidad es eso que nos permite de definir eso que importa o no importa para nosotros" (TAYLOR, 1998, p. 65). Ella permite al "yo" desarrollar auto-comprensiones que lo sitúan en una "carta moral". En esta perspectiva la identidad es una noción moderna ya que ella necesita la autonomía y se liga a la percepción de sí y a su propia legitimación. La identidad se dibuja a partir de la articulación de valores morales que me distinguen de aquellos de otro (individual o colectivo). La identidad concilia pues la referencia a la autonomía individual y la comunidad de pertenencia. Existen entonces tres ejes complementarios de 
la identidad: una obligación de posicionamiento de sí sobre un horizonte compuesto de valores; una insistencia sobre la importancia moral de las diferencias que establece un vínculo entre dignidad, diferencia y necesidad de reconocimiento; una apertura comunitaria que proviene del paralelismo entre la identidad del individuo y la del grupo.

Desde esto tres ejes se puede afirmar que la identidad representa mi universo moral "la identidad define eso que nosotros somos y de dónde venimos" (TAYLOR, 2007, p. 59). La identidad por lo tanto demanda una capacidad reflexiva para discriminar moralmente lo que tiene importancia para nosotros. La identidad no puede ser deducida exteriormente del lugar que le era atribuido en el orden de cosas, siguiendo linajes o pertenencias, dependiente de un arquetipo exterior al cual el ser humano se debía adecuar. La definición del horizonte moral desde el cual me sitúo llega a ser una cuestión personal. La autonomía juega un rol importante en esa interiorización de normas, el sujeto debe discernir sus objetivos en él, incluso cuando se dirigen a Dios a la vida en sociedad, ellos requieren un consentimiento personal y racional.

Al mismo tiempo la identidad presupone una valorización de la de la particularidad y de la diferencia. La identidad resultará de un juego de negociación entre eso que yo creo de original y mi historia, la comunidad de pertenencia, la tradición y todo aquello que me han legado los "otros dadores de sentido" (TAYLOR, 1994, p. 44). Ello implica que a pesar de una estricta conformidad con la tradición, la identidad necesita una adquisición-aprehensión de mi parte. La identidad moderna responde a la pregunta quién soy, à través de valores, de pertenencias a una colectividad. La aptitud a hacer preguntas sobre aquello que tiene más valor y a responder, se actualiza dentro de una comunidad.

El yo, según Taylor, es no auto-suficiente, ello significa que "tenemos necesidad del concurso de otros significativos" (TAYLOR, 2007, p. 61). El objetivo de la búsqueda identitaria no es un control racional de sí, sino el hecho de dar sentido a la vida concebida como un todo. De esta manera la identidad debe ser completada por la naturaleza dialógica de la identidad y la necesidad de reconocimiento por otro. Es decir el yo, ese ser de identidad, no puede ser estudiado sin considerar las interpretaciones que dan los sujetos mismos. El hombre no es un "yo" sino en el seno de 
una comunidad, ella constituye la referencia verdadera en la construcción de la identidad ya que la cultura de la comunidad es la que lega nuestros referentes morales. Por otro lado la construcción de sí es correlativa a los intercambios con los otros, permitiendo que ella se encuentre en continua elaboración hasta el punto de llegar a admitir que mis "pertenencias" puedan ser múltiples, revocables y evolutivas. La aceptación del otro, en cuanto elemento constitutivo de mi identidad, conduce a la puesta en práctica de una política de reconocimiento que promueva el diálogo colectivo, creador de identidad.

Para Taylor (2007, p. 61). el carácter dialógico de la identidad hace del reconocimiento "la condición de la identidad lograda". Al considerar que la identidad es formada o deformada por el diálogo con los otros, las relaciones sociales aparecen como lugar del descubrimiento y de la generación de sí, generando una fuerte necesidad de reconocimiento. Esa necesidad se manifiesta tanto a nivel personal, como a nivel social y público. El objetivo verdadero de la búsqueda de reconocimiento es la comunidad y solo en ella se da respuesta posible al reconocimiento (comunidad que se entiende como espacio trascendente de compromiso mutuo). La necesidad de reconocimiento subraya igualmente la dimensión afectiva, vital, de la valorización de la identidad moderna en la esfera pública. Esta necesidad de reconocimiento toma hoy la forma de una política que valora la diferencia y se encuentra en relación con la igualdad. Esta política de reconocimiento-diferencia nos lleva a considerar que todos los seres humanos tienen una especificidad y es por ello que la exigencia universal de la dignidad exige el reconocimiento de lo específico en la esfera de lo público. La política de la diferencia enuncia un reconocimiento de la igualdad de todas las posibilidades humanas realizadas de forma diferente, pero fundamentalmente enuncia un reconocimiento de la igualdad de los valores culturales. Taylor defiende el principio kantiano según el cual la dignidad humana consiste en su autonomía, en la capacidad que tiene cada persona de determinar su propia concepción de vida ideal.

La reflexión tayloriana entorno a la identidad-reconocimiento-diferencia se ha traducido en el ámbito educativo de sociedades desarrolladas. Un ejemplo concreto es el caso de la Provincia de Québec donde después de procesos serios de desconfensionalización de estructuras escolares 
y de la enseñanza religiosa, de considerar el respecto de la libertad de consciencia y de religión, de la neutralidad de la escuela pública, de superar una educación moral para todos, el ministerio de educación, recreación y deporte ${ }^{7}$ ha fijado algunas orientaciones: definir un único programa de ética y de cultura religiosa que reemplace los programas confesionales y el programa de moral; aprendizajes continuos y progresivos; aprendizajes enraizados en la realidad del joven y la cultura quebequense; aprendizajes que respeten la libertad de conciencia y de religión; aprendizajes que favorecen el vivir juntos. En cuanto a las orientaciones ministeriales para el contenido de la Educación religiosa se encuentran: la familiarización con la herencia religiosa de Quebec; la apertura a la diversidad religiosa; la capacidad de situarse de manera reflexiva frente a las religiones y los nuevos movimientos religiosos; la toma en cuenta de representaciones del mundo y del ser humano diferentes de las religiosas.

La cultura religiosa consiste ${ }^{8}$ consiste en una comprensión de los principales elementos constitutivos de las religiones que reposa sobre el universo socio-cultural en las cuales ellas se enraízan y evolucionan. Estos diversos elementos de la cultura religiosa permitirán a los estudiantes de comprender progresivamente el fenómeno religioso en sus dimensiones experiencial, histórica, moral, ritual, artística, social o política. En la elaboración de situaciones de aprendizaje se tiene en cuenta: el cristianismo (catolicismo y protestantismo), el judaísmo, el Islam, el budismo, el hinduismo y las espiritualidades amerindias; junto a esto otras expresiones culturales de representación del mundo y del ser humano que definen el sentido y el valor de la experiencia humana fuera de las creencias y de las adhesiones religiosas son también abordadas. En este Programa se da una mirada privilegiada sobre: el patrimonio religioso de la sociedad quebequense, la importancia histórica-cultural del catolicismo y protestantismo en Québec. Cada convicción y religión es tratada a nivel de conocimientos, de fenómenos y no de fe.

7 MINISTÈRE DE LEÉDUCATION, DU LOISIR ET DU SPORT. La mise en place d'un programme d'éthique et de culture religieuse: une orientation d'avenir pour tous les jeunes du Québec. 2005. Disponible à l'adresse: <http://www.mels.gouv.qc.ca/cpress/cprss2005/c050504.asp>. Accéder: 20 sept. 2011.

8 Versión aprobada del Programa ética y cultura religiosa. CONFERENCIA EPISCOPAL COLOMBIANA. Lineamientos y estándares curriculares para la Educación Religiosa. Colombia: Conferencia Episcopal, 2004. p. 7-8. 
El Programa tiene como finalidades: el reconocimiento del otro, en su visión de mundo, en sus convicciones religiosas o seculares, en los diversos elementos de construcción de identidad - indisociable de un conocimiento de sí este aspecto contribuye a la construcción de una cultura pública común que tiene en cuenta la diversidad-; búsqueda del bien común, la búsqueda conjunta de valores comunes, la valorización de proyectos que privilegian el vivir-juntos, la promoción de principios e ideales democráticos. Las competencias a desarrollar son: reflexionar sobre cuestiones éticas (discernir o analizar situaciones desde el punto de vista ético. Examinar algunos referentes significativos de orden cultural, moral, religioso o científico y evaluar opciones y acciones posibles); manifestar una comprensión del fenómeno religioso (explorar y analizar expresiones de lo religioso, vínculos de éstas con el medio socio-cultural y considerar-examinar una diversidad de maneras de pensar, de ser y de actuar); practicar el diálogo (organizar el pensamiento, interactuar con otros y construir un punto de vista).

Junto a esta Educación ética y de cultura religiosa el artículo 36 sobre la instrucción pública considerando que la escuela debe facilitar el caminar espiritual del estudiante con el fin de favorecer el desarrollo y despliegue de sus posibilidades como ser humano integral. Se trata de "elevar el estudiante en humanidad", de facilitar su humanización y su deseo de superación. La humanidad es un proyecto que se construye sobre la dignidad de cada persona y reconocida con las leyes, las religiones y las sociedad misma. Este caminar espiritual lleva a considerar al estudiante que su desarrollo no solo se limita a la cualificación y avance profesional sino a una cierta búsqueda de sentido, a una vida del espíritu, interior. Apesar que la espiritualidad hace referencia a una búsqueda de sentido y a una trascendencia sin nombre y más horizontal menos institucionalizada, ella no excluye relación con una religión. El caminar espiritual no es una educación a la espiritualidad o espiritualidades, sino activar en el estudiante una predisposición a entrar en él mismo para allí descubrir eso que lo hace vivir en tanto que ser humano integral. Algunos aprendizajes son necesarios en este caminar espiritual: la aptitud a la libertad, la aptitud a la interioridad, el coraje de ser, la construcción de sí y del sentido de la alteridad y la aptitud de responsabilidad. Este caminar espiritual del 
estudiante es una responsabilidad común de la escuela y sus miembros. Este caminar requiere tomar en serio eso que el estudiante es en la situación presente; acogerlos en su experiencia espiritual propia, con los trazos culturales que los caracterizan.

\section{Prospectivas}

No cabe duda que la Educación Religiosa Escolar en Colombia continúa siendo, en el contexto de la escuela privada, confesional-católica. Las definiciones de lineamientos y estándares curriculares ponen de manifiesto esta primacía del catolicismo. En la escuela pública se percibe, debido a la falta de formación de maestros y por una cierta laicización de la educación, un panorama menos claro, más homogéneo. El lugar de la Educación Religiosa Escolar parece ser menos confesional, diverso, adolece de finalidad clara. Quién se hará responsable y tomará en serio este escenario de la Escuela Pública para pensar la relevancia, pertinencia y objetivo de la Educación Religiosa Escolar. La Iglesia Católica, a través de la Conferencia Episcopal Colombiana se ha "hecho responsable" de pensar, definir y dar orientaciones sobre una Educación religiosa confesional, con intereses evangelizadores, catequéticos, evidenciándose un cierto "eclesiocéntrismo".

Varios desafíos se imponen progresivamente para comprender una Educación Religiosa Escolar que responda a los desafíos socio-culturales, a la construcción de subjetividad, a la formación integral e integradora, entre ellos percibimos: una responsabilidad compartida Iglesia católica-escuelareligiones; una integración del currículo de la ERE con otros saberes, experiencias y credos religiosos; la diferenciación de la Educación Religiosa Escolar y la Educación en la fe; un respeto a la autonomía de la escuela, de la construcción de un currículo crítico y emancipador que no permita el "instrumentalizar" la escuela al servicio de intereses ni políticos, ni religiosos; una toma en serio de la teología del diálogo interreligioso que facilite la superación del exclusivismo e inclusivismo eclesial; un diálogo interreligioso y ecuménico que se traduzca en lineamientos y estándares curriculares construidos en "responsabilidad compartida" con otras religiones; un reconocimiento del valor de otras religiones que supere la brecha que traza 
el comprender religiones reveladas y naturales; una Educación Religiosa Escolar que desarrolle competencias en torno a la tolerancia, la reciprocidad y el civismo; una formación integral que tome en serio el conocimiento (una hermenéutica crítica y preformativa de las religiones, lo religioso y la espiritualidad) y el reconocimiento (el aprender a vivir juntos).

\section{Referencias}

CONFERENCIA EPISCOPAL COLOMBIANA. Escuela y religión. Colombia: Conferencia Episcopal, 2000.

CONFERENCIA EPISCOPAL COLOMBIANA. Lineamientos y estándares curriculares para la Educación Religiosa. Colombia: Conferencia Episcopal, 2004. MINISTÈRE DE L'ÉDUCATION, DU LOISIR ET DU SPORT. La mise en place d'un programme d'éthique et de culture religieuse: une orientation d'avenir pour tous les jeunes du Québec. 2005. Disponible à l'adresse: <http://www. mels.gouv.qc.ca/cpress/cprss2005/c050504.asp>. Accéder: 20 sept. 2011.

QUELLET, F. Quelle formation pour l'éducation à la religion. Québec: Presses de l'Université Laval, 2005.

SHEEHY, G. Passages: predictable crises of adult life. New York: Bantam, 1976. TAYLOR, C. Multiculturalisme, différence et démocratie. Paris: Aubier, 1994. TAYLOR, C. Hegel et la société moderne. Paris: Cerf, 1998.

TAYLOR, C. Fuentes del yo: La construcción de la identidad moderna. Barcelona: Surcos, 2006.

TAYLOR, C. Grandeur et misère de la modernité. Canadá: Bellarmin, 2007.

Recibido: 22/05/2011

Recebido: 22/05/2011

Aprobado: $23 / 07 / 2011$

Aprovado: 23/07/2011

Rev. Pistis Prax., Teol. Pastor., Curitiba, v. 4, n. 1, p. 197-214, jan./jun. 2012 